\title{
UNA PRUEBA DEL CARÁCTER CONFEDERAL DE LA UNIÓN EUROPEA: EL MANTENIMIENTO DE LA UNANIMIDAD ESTATAL EN EL PROCESO DE REVISIÓN DEL TRATADO POR EL QUE SE ESTABLECE UNA CONSTITUCIÓN PARA EUROPA* ${ }^{(*)}$
}

\author{
NOEMI GARCIA GESTOSO \\ Profesora Dra. de Derecho Constitucional \\ Universidad de Vigo
}

SUMARIO

I. Introducción.

II. La reforma de la norma básica en las formas históricas del federalismo.

III. El procedimiento de revisión de los Tratados comunitarios.

IV. El procedimiento de reforma en el Tratado por el que se establece una constitución para Europa.

V. ¿Constitución o Tratado?

\section{INTRODUCCION.}

El análisis del modo de proceder a la modificación formal de la norma fundamental en que se basan las formas históricas del federalismo - Confederación y Estado federalcumple un papel esencial a la hora de establecer la diferencia entre ambos tipos clásicos. Diferencia que, como se verá, incide decisivamente en la configuración del Estado federal como Estado Constitucional, y, asimismo, en la no identificación de la Confederación con este último. Esta distinción va a cobrar especial relevancia al ser aplicada al proceso de

(*) Este trabajo constituye una versión reelaborada y actualizada de la comunicación presentada en el VIII Congreso Iberoamericano de Derecho Constitucional celebrado en Sevilla los días 3 al 5 de diciembre de 2003. 
texto se firmó el 29 de octubre de 2004. Tras lo cual, se intentarán extraer conclusiones del estudio realizado al ámbito comunitario en el momento presente.

\section{LA REFORMA DE LA NORMA BASICA EN LAS FORMAS HISTORICAS DEL FEDERALISMO}

\section{LA REFORMA EN LA CONFEDERACIÓN CLÁSICA.}

Indisociablemente ligado al carácter contractual del pacto que da vida a una Confederación de Estados se presenta el procedimiento para proceder a su reforma. No hay que olvidar que la naturaleza de este vínculo se basa en un acuerdo libre y voluntario entre Estados soberanos que van a seguir siéndolo, y no en relaciones propiamente de Derecho Constitucional. Nada tiene de extraño entonces que la forma de preservar ese carácter especial del compromiso de asociación condicione decisivamente el modo en que puede reformarse. Aparece como requisito consustancial para que sea aprobada una reforma del pacto originario de la Confederación la exigencia del consentimiento unánime de los Estados que en ella participan. Exigencia que tiene por objetivo proteger su soberanía estatal, y que se plasma, desde el punto de vista jurídico, ya sea en un derecho de veto que impide el cambio, ya en el derecho de separarse de esa asociación si no aceptan tal modificación. Todo ello, a la postre, no es más que el fiel reflejo de que en el estadio confederativo los Estados participantes siguen siendo los dueños supremos de su destino, esto es, siguen siendo soberanos.

El análisis de los modelos históricos que han existido de Confederación - Unión de las trece antiguas Colonias americanas desde el 15 de noviembre de 1777, fecha en que son aprobados los «Articles of Confederation», hasta la puesta en marcha de la Convención de Filadelfia, el 25 de mayo de 1787 y subsiguiente aprobación de la Constitución federal estadounidense; la Confederación Helvética desde 1803 a 1848; y la Confederación Germánica entre los Länder alemanes desde 1815 hasta la creación del Imperio guillermino en 1870 y la aprobación de la Constitución de $1871^{2}$-, sobre los cuales se ha formulado su concepto clásico, avalan estas afirmaciones.

En todos estos casos la base de la Confederación es un Tratado Internacional, en el cual se prevé que cualquier modificación en su articulado ha de contar con el consentimiento unánime de todos los Estados confederados ${ }^{3}$. También en estos supuestos nos encontramos que la forma confederal constituye el primer paso de un proceso asociativo cuya evolución posterior culminará en la unidad nacional y en la vertebración de un Estado propiamente federal. Hay un momento en el que se produce un cambio cualitativo y se produce una ruptura respecto a la situación anterior. En vez de reforma de la base contractual de la Confederación por unanimidad, conforme lo estipulado, se elabora y aprueba una Constitución. Constitución que entra en vigor de distinta manera a la prevista para revisar

la Confederación precedente y que refleja la existencia de un Poder Constituyente origina-

1 Cfr. RUIPEREZ, J., La «Constitución Europea» y la teoría del Poder Constituyente, Madrid, 2000, pp. 40-41. 
integración europeo. En efecto, la Unión Europea se presenta como una organización de Estados cuya naturaleza jurídica es difícil de establecer. Ahora bien, resulta evidente que la construcción europea se erige sobre los esquemas del federalismo entendido en sentido amplio, esto es, comprendiendo tanto a la Confederación como al Estado propiamente federal. El problema radica en determinar a cuál de estas dos manifestaciones estructurales históricas se puede adscribir esta nueva entidad política ${ }^{1}$. En este sentido, el estudio comparado de los procedimientos de reforma de sus normas constitutivas permite extraer conclusiones valiosas para aprehender el estadio actual de la Unión Europea así como de la evolución que se pretende en el proyecto de reforma en curso.

Desde esta perspectiva el objetivo del presente trabajo es, en primer lugar, efectuar una síntesis de los distintos procedimientos de revisión del pacto constitutivo en las distintas Confederaciones que han existido a lo largo de la historia y respecto a las cuales se ha procedido a formular el concepto tradicional de la misma, incidiendo en su significado y justificación. En segundo término, se procederá a analizar esta temática en el marco del Estado federal. Seguidamente, se esbozarán los principios básicos del procedimiento vigente a seguir para modificar los Tratados constitutivos de las Comunidades y de la Unión Europea. Se plantearán los problemas que derivan de ese mecanismo, a la vez que se exponen otras propuestas que se han planteado en la historia del proceso integrador. Finalmente, se estudiará qué prevé al respecto el Proyecto de Tratado por el que se instituye una Constitución para Europa tal y como resulta del texto emanado de la Convención así como de la versión resultante de tal Tratado tras la Conferencia intergubernamental finalizada en junio de 2004 cuyo

2 Sobre estos modelos históricos, cfr. BORGEAUD, Ch., Établissement et revisión des Constitutions en Amérique et en Europe, Paris, 1893, pp. 57-77, 157-164, 309-357; PEREZ SERRANO, N., Tratado de Derecho Político, 2a. ed, Madrid, 1984, pp. 235-237, 491-492, 513-515, 563-565; GARCIA PELAYO, M., Derecho constitucional comparado, $1^{\mathrm{a}}$. ed., 3a. reimpr., Madrid, 1993, pp. 209-214, 325-337, 521-533; LUCAS VERDU, P., Curso de Derecho Político, vol. II: La crisis de la teoría del Estado en la actualidad. Federalismo y Estado federal. La teoría de la Constitución en el marco del Derecho político, $3^{\text {a }}$. ed., $2^{\text {a }}$. reimpr., Madrid, 1989, pp. 285-302; AUBERT, J.-F., «L'évolution historique des confédérations», en VVAA, Le concept contemporain de Confédération, Strasbourg, 1995, pp. 17-38; Idem, «Estado, Nación y Soberanía. Suiza.», en PEREZ CALVO, A., (Coord.), Estado, Nación y Soberanía. (Problemas actuales en Europa), Madrid, 2000, pp. 410-413.

3 En realidad las colonias norteamericanas iniciaron un proceso de aproximación progresivo ya bajo dominio británico, reuniéndose en diversos congresos, que más tarde adoptaría la forma de Congreso continental, cuya primera reunión data de 1774. El proyecto de los Articles of Confederation fue redactado por una comisión creada por el segundo Congreso continental el 11 de junio de 1776, antes de la proclamación de independencia de 4 de julio de 1776. En los «Articles of Confederation» se indican nominativamente todos y cada uno de los distintos sujetos estatales que suscriben esa Confederación, recibiendo el texto definitivo la aprobación del Congreso el 15 de noviembre de 1777. Al ser un Tratado internacional, como tal fue ratificado por todos los nuevos Estados entre 1778 y 1781. En su art. XIII se establece que cualquier reforma en éstos ha de ser aprobada en un Congreso de los Estados Unidos y confirmada por las legislaturas de todos los Estados. Respecto a la Confederación Helvética interesa resaltar que cuando Suiza recobra su independencia frente a los franceses y puede escoger libremente su forma de gobierno, procederá a darse una nueva estructura confederal sobre la base del Pacto de 7 de agosto de 1815. La naturaleza jurídica que reviste este compromiso asociativo es la propia de un Tratado Internacional, creador de una Confederación. Lo cual se manifiesta, entre otros extremos, en su previsión de que para su revisión se necesita la participación y aprobación de todos los cantones que lo suscribieron. La Confederación Germánica se basa en el Tratado de 8 de junio de 1815, denominado Acta federal alemana, completado el 15 de mayo de 1820 por un segundo Tratado, conocido como el Acta final de Viena. El procedimiento de reforma por unanimidad se recoge en los arts. 7 del Acta de 1815 y 12 y 13 de la de 1820. 
por la peculiar forma de organización territorial del poder a que responde, aunque se encuadra dentro del concepto de reforma constitucional y de las funciones genéricas que tiene atribuidas este instituto en la moderna organización constitucional democrática ${ }^{4}$. Así, es dentro de este contexto desde donde hay que partir habida cuenta del carácter estatal de tal forma de organización política, cuya Ley suprema reviste todos y cada uno de los caracteres que deben concurrir para calificarla como Constitución en sentido propio ya que se presenta como resultado de un acto del Poder Constituyente del Pueblo federal en su conjunto, esto es, actuando como unidad de acción política que ha previamente realizado el pacto social.

Ahora bien, resulta que el principio de rigidez, inherente al concepto moderno de Constitución, es si cabe, aún más relevante en un Estado federal en razón de que al instituto de reforma constitucional, en esta forma estatal, le corresponde cumplir la función específica de garantizar la indisponibilidad unilateral de las previsiones sobre el reparto de competencias establecida en la Constitución federal. Este objetivo es el que da su carácter peculiar al procedimiento previsto para modificar la Constitución, y se manifiesta en la necesidad de que participen tanto los órganos federales como los Estados miembros en la operación de reforma. La razón se encuentra en que se presenta, a la postre, como un instrumento inexcusable para la protección y garantía de la autonomía de las colectividades miembros que integran el Estado federal

Por lo expuesto, y pese a las dificultades sobradamente conocidas que existen para establecer un concepto genérico de Estado federal, la doctrina mayoritaria considera que el elemento definidor del Estado federal reside en la protección constitucional de la autonomía, que se articula jurídicamente mediante el establecimiento de una Constitución escrita y rígida, y, asimismo, a través de la existencia de algún sistema de justicia constitucional que asegure su supremacía 6 .

Nada tiene de extraño entonces que sea en el marco del establecimiento de una Constitución federal donde se suscite por primera vez, tanto en el plano teórico como jurídico, la necesidad de que sea el propio Texto Constitucional el que establezca previsiones que dificulten las alteraciones de su texto sin llegar a impedirlas, y que, para ello, se estipule un procedimiento específico destinado a garantizar que perdure el equilibrio en que descansa un Estado federal

Así las cosas, en el procedimiento de reforma de la Constitución de un Estado federal concurren estas características: la necesaria participación de las colectividades miembros y de la organización política central en la operación de reforma, y, dentro de sus diversas fases, siempre en la de aprobación; la aprobación por parte de los Estados miembros se dilucida por la regla mayoritaria; la reforma aprobada válidamente obligará a los miembros que se hayan pronunciado en contra, ya que no se les reconoce, en ningún caso, un derecho de veto individual ni de secesión. Estas reglas se corresponden con una perspectiva genérica de los rasgos de la reforma constitucional dentro de la categoría del Estado federal, encontrándonos en el Derecho positivo comparado diversas excepciones ${ }^{8}$

Sea de ello lo que fuere, lo importante es indagar acerca del fundamento de la intervención obligada de los miembros en la reforma. Algunos autores encuentran su justificación en el origen contractual del Estado federal, por lo que concluyen que en la reforma de tal convenio han de intervenir las mismas partes que lo suscribieron originariamente. No obstante, frente a esta tesis se alza el propio concepto de Poder Constituyente y Constitución que 
rio.

De lo expuesto, resulta evidente pues, que la férrea regla de la unanimidad en la reforma del vínculo constitutivo de la Confederación y el consiguiente derecho de veto forman parte de la armadura tradicional de esta forma histórica del federalismo ligados a su base pacticia. Y no se puede olvidar que siempre se ha admitido la resolución de un vínculo contractual entre soberanos. Todo ello no hace sino demostrar que en el estadio confederal los Estados miembros son los que siguen accionando directamente los resortes del poder central. Frente a esto, en el Estado Federal esta norma es significativamente distinta.

Por otra parte, el estudio de los modelos históricos anteriores, parece confirmar las teorías que ven la Confederación como un estadio intermedio y necesariamente transitorio entre los Estados soberanos y el Estado federal, de suerte que está destinada inevitablemente a pasar de un estadio a otro o desaparecer. En los tres procesos se transforma una Confederación de Estados en un Estado federal. Transformación que se produce por procedimientos distintos a los previstos para la modificación de las Confederaciones precedentes y que deja su impronta en el nuevo procedimiento que se prevé para las futuras reformas que ya no necesitarán unanimidad. Que sea la estructura federal el punto de llegada en los tres supuestos resulta fácilmente comprensible dado el carácter estatal previo de los miembros de la Confederación. De esta manera aunque terminan perdiendo los atributos de la estatalidad, no cabe duda de que conserva una posición jurídica sólida que se traduce sobre todo en un derecho de decisión y participación.

Si uno se interroga sobre las razones profundas que motivaron estas transformaciones, parece indudable que hay que atribuir un peso primordial a la existencia de una idea nacional que actúa como fuerza centrípeta. El modo concreto a través del cual se han producido las transformaciones se presenta, sin embargo, diferente.

\section{LA REFORMA de la CONSTITUCiÓn EN EL Estado FEderal.}

La reforma de la Constitución federal en tal tipo de Estados se encuentra mediatizada

4 Sobre la reforma constitucional, cfr., por todos, DE VEGA, P., La reforma constitucionaly la problemática del Poder Constituyente, Madrid, 1985, passim.

5 Cfr., por todos, RUIPEREZ, J., Formación y determinación de las Comunidades Autónomas en el ordenamiento constitucional español, 2a . ed., Madrid, 1991, pp. 46-47; Idem, La protección constitucional de la autonomía, Madrid, 1994, pp. 75-118; Idem, La constitución del Estado de las autonomias. Teoría constitucional y práctica política en el federalizing process español, Madrid, 2003, pp. 228-248.

6 Cfr. FRIEDRICH, C.J., El hombre y el Gobierno. Una teoría empírica de la política, Madrid, 1968, pp. 636-637; Ídem, Tendences du fédéralisme en théorie et en practice, Bruxelles, 1971, p. 30; Ídem, Gobierno Constitucional y Democracia. Teoría y práctica en Europa y en América, vol. I, Madrid, 1975, pp. 388-389; y DURAND, Ch., Les États féderaux. Étude de Droit Constitutionnel Positif, Paris, 1930, pp. 93-94 y 336-337; Ídem, «El Estado federal en el Derecho Positivo», p. 180, en BERGER, G., y CHEVALLIER, J.J., y otros, Federalismo y federalismo europeo, Madrid, 1995.

7 Como señala LA PERGOLA, A., Residui «contrattualistici» e struttura federale nell'ordinamento degli Statu Uni, Milano, 1969, pp. 192-193, el principio de rigidez constitucional obtuvo su primera formulación en íntima conexión con el fenómeno del Estado federal, expandiéndose posteriormente más allá de la estructura estatal federal para convertirse en un principio nuclear de la propia noción de Constitución en su sentido moderno. 
nales, unidad que constituye el principio esencial común a ambas. Desde la perspectiva de las colectividades miembros es precisamente a través de su participación en el poder federal como éstos pueden expresar su naturaleza política incorporándose, al mismo tiempo, al conjunto. En el fondo, éste es el fundamento de las llamadas relaciones de inordinación características del Estado federal, entre cuyas principales manifestaciones se encuentran la participación de los Estados miembros en la legislación de la Federación a través de su presencia y actuación en una segunda Cámara y su intervención en la reforma constitucional. Es dentro de las funciones a las que sirven estas relaciones donde se dilucida la auténtica naturaleza de la reforma en el Estado federal, coligiéndose que esta participación de los miembros en la revisión de la Constitución federal la realizan como elementos de la propia Federación, a cuyo través concurren a la integración del sistema. Y éste es también el sentido de la participación combinada con los órganos centrales en la reforma de la Constitución federal.

\section{EL PROCEDIMIENTO DE REFORMA EN LOS TRATADOS COMUNITARIOS.}

Los Tratados fundacionales de las Comunidades y de la Unión Europea formalmente se presentan como un conjunto de Tratados de Derecho Internacional. No obstante, se suelen señalar una serie de rasgos que los diferencian nítidamente del Derecho convencional clásico dentro de un proceso de constitucionalización de dichos Textos que busca independizarlos de tal cuerpo de Derecho, incidiendo en el carácter autónomo del ordenamiento jurídico a que dan lugar. Dentro de esas notas singulares, destaca el modo de proceder a su revisión una vez que han entrado en vigor.

Cierto es que tales Tratados han sido concluidos con una duración ilimitada, y con el fin de encuadrar un proceso de integración progresiva entre los pueblos de Europa, lo que conduce a su modificabilidad. Por ello, no resulta extraño que prevean en su propio seno los procedimientos para llevar a cabo su revisión. Precisamente, a través de su reforma, se busca conciliar, en el desarrollo de ese proyecto integrador, las exigencias inherentes a cualquier ordenamiento jurídico de estabilidad y adaptabilidad. Exigencias que son especialmente acuciantes en el devenir de la Unión Europea. La estabilidad aparece como una necesidad existencial para desarrollar un proyecto de integración complejo, que ha de

8 Vid. las principales excepciones en RUIPEREZ, J., La protección constitucional..., op. cit., pp. 88-89 y $92-94$. Por otra parte, dentro del Derecho positivo, resulta esclarecedora la clasificación que realiza Ch. DURAND, «El Estado federal en...», cit., pp. 204-205, de los distintos Estados federales existentes en relación con el tipo y grado de participación que ostentan los Estados miembros en la reforma constitucional.

9 Cfr., entre otros, RUIPEREZ, J., La protección constitucional..., op. cit., pp. 93-99; GONZALEZENCINAR, J.J., El Estado unitario-federal: la autonomía como principio estructural del Estado, Madrid, 1985, p. 83.

10 Cfr. BRYCE, J., Constituciones flexibles y Constituciones rígidas, Madrid, 1988 pp. 119-120; BURDEAU, G., Traité de Science Politique, tomo II: L'État, 2a . ed. revisada y aumentada, Paris, 1967, p. 492; BURGESS, J. W., Ciencia Politica y Derecho Constitucional comparado, vol. I: Soberanía y libertad, Madrid, 1922, pp. 174-175; CARRÉ DE MALBERG, R., Teoría general del Estado, 2a. ed., México, 1998, pp. 121-122; WHEARE, C., Federal Government, $3^{\mathrm{a}}$. ed., London/New York/Toronto, 1953, p. 57; LOEWENSTEIN, K., Teoría de la Constitución, $2^{\mathrm{a}}$. ed., $1^{\mathrm{a}}$. reimpr., Barcelona, 1982, pp. 182-183; FRIEDRICH, C.-J., El hombre..., op. cit., p. 637. 
actúan en el Estado federal. La Constitución federal es obra del Poder Constituyente originario, que como tal es ilimitado. Desde estos axiomas básicos del constitucionalismo, se entiende la imposibilidad lógica de cualquier intento de fundamentar la intervención de los Estados miembros si no es en la propia voluntad del Poder Constituyente recogida en la Constitución estableciendo un procedimiento de reforma que así lo estipula ${ }^{9}$

En el fondo, la razón que justifica la intervención de los miembros en la modificación constitucional es la finalidad garantista de la subsistencia política tanto de las organizaciones regionales como de la Federación. En suma, de la propia forma federal. Por lo tanto, lo determinante para aprehender y caracterizar el Estado federal es que estén constitucionalmente protegidos ambos niveles de decisión.

Sentado lo anterior, es necesario reflexionar sobre el modo en que se produce la aprobación de la reforma por parte de las colectividades-miembros. Como se ha señalado, la norma general es que se asegure la participación y el derecho al voto de los Estados componentes dentro de tal operación de modificación. Pero para aprobarla nunca se exige la unanimidad sino que se usan criterios mayoritarios, bien mayoría absoluta bien mayorías cualificadas. De ahí que el modo en que se produce la decisión de los miembros sobre la reforma, constituya el criterio más esclarecedor para contraponer el Estado federal y la Confederación de Estados ${ }^{3}$.

El significado último de esta regla mayoritaria, y la consiguiente inexistencia de derecho de veto en cada uno de los Estados miembros, se encuentra en la caracterización del Estado federal como Estado Constitucional, en el que, por lo tanto, la soberanía en el funcionamiento jurídico del mismo reside en la Constitución federal. Constitución que encuentra su origen en la actuación de un Poder Constituyente unitario, el del Pueblo federal. A partir de entonces, sólo la Constitución es soberana. Desde estas premisas se colige que los Estados miembros ya no son soberanos, ni tampoco la organización central.

En el Estado federal se ha producido el hecho nacional en el sentido jellinekiano. Quiere esto decir que antes de la aprobación de la Constitución se ha celebrado el pacto social que afirma la voluntad de vivir juntos en una unidad superior que los englobe. De esta suerte, ha surgido un nuevo titular unitario del Poder Constituyente, a saber, el Pueblo federal en su conjunto, que como tal ejercita su facultad constituyente articulando el nuevo Estado que por su decisión soberana desean se asiente sobre una base federal y para ello aprueban una Constitución que organiza y garantiza esta forma determinada.

Sobre estas premisas ha de entenderse que la modificación de la Constitución federal se presenta como acto propio del Estado federal en su conjunto ${ }^{11}$. Se ha de partir de la simbiosis que se produce en el Estado federal entre unidad y pluralismo que impide entender esta peculiar forma estatal como una simple yuxtaposición entre distintos centros de decisión y diferentes ordenamientos jurídicos. Es algo más. Como observa R. SMEND ${ }^{12}$, de lo que se trata es de conseguir alcanzar la unidad vital entre organización central y regio-

11 Esta es la postura que sostiene la doctrina mayoritaria. Cfr., por todos, CARRÉ DE MALBERG, R., Teoría general del Estado, $2^{\mathrm{a}}$. ed., op. cit., pp. 122-133.

12 Cfr. SMEND, R., «Constitución y Derecho Constitucional», en el vol. Constitución y Derecho Constitucional, Madrid, 1985, p. 178, pp. 236-237. 
que dan vida a las tres originarias Comunidades, ya aparecen en los distintos Tratados fundacionales previsiones regulando los procesos que habían de seguirse para ser modificados —antiguos artículos 236 TCEE, 204 TCEEA, 96 TCECA—. Solo se reproducirán las previsiones del TCEE y del TCECA porque el artículo 204 del TCEEA es literalmente idéntico al concordante del TCEE.

Art. 236 TCEE: «El gobierno de cualquier Estado miembro, o la Comisión, podrá presentar al Consejo proyectos dirigidos a la revisión del presente Tratado./Si el Consejo, previa consulta al Parlamento Europeo y, en su caso, a la Comisión, emite un dictamen favorable a la reunión de una conferencia de los representantes de los Gobiernos de los Estados miembros, ésta será convocada por el presidente del Consejo, con el fin de que se aprueban de común acuerdo las modificaciones que deban introducirse en el presente Tratado./Las enmiendas entrarán en vigor después de haber sido ratificadas por todos los Estados miembros, de conformidad, con sus respectivas normas constitucionales».

Art. 96 TCECA: «Transcurrido el período transitorio, el Gobierno de cada Estado miembro y la Alta Autoridad podrán proponer enmiendas al presente Tratado. Esta propuesta será sometida al Consejo. Si éste emitiere, por mayoría de dos tercios, un dictamen favorable a la reunión de una conferencia de representantes de los Gobiernos de los Estados miembros, ésta será inmediatamente convocada por el presidente del Consejo, a fin de adoptar de común acuerdo las enmiendas que deban introducirse a las disposiciones del Tratado./ Las enmiendas entrarán en vigor tras haber sido ratificadas por todos los Estados miembros, de conformidad con sus respectivas normas constitucionales».

Pese a que el procedimiento previsto originariamente con carácter general para revisar el TCECA resultaba un poco distinto al establecido para la revisión de los otros tratados, esas diferencias no presentan un carácter sustancial, apreciándose la similitud de fondo entre estos procedimientos. En definitiva, establecen un sistema de reforma basado en el predominio intergubernamental, acorde con la norma general de Derecho Internacional para modificar los Tratados, recogiendo de manera explícita la necesidad del acuerdo de todos los Estados miembros y su posterior ratificación nacional.

\section{LA UNIFICACIÓN DE LOS PROCEDIMIENTOS REALIZADA POR EL TUE.}

Posteriormente, con el Tratado de Maastricht, se establece un único procedimiento para la modificación formal de los Tratados sobre los que se funda la Unión. Procedimiento que se prevé dentro de las Disposiciones finales, en su art. N, apartado primero, que dispone:

13 En efecto, el ordenamiento jurídico comunitario presenta entre sus rasgos más específicos su evolución constante. Cfr., por todos, RODRIGUEZ IGLESIAS, G.C., «Consideraciones sobre la formación de un Derecho Europeo», Gaceta Jurídica de la Comunidad Europea y de la Competencia, n. 200, 1999, pp. 11-25.

14 Ahora bien, no se puede olvidar que este planteamiento es criticable, ya que sólo se puede hablar propiamente de rigidez constitucional a partir de la experiencia de la Constitución federal norteamericana, cuando al bastar para aprobar su reforma una mayoría cualificada, se abandonan los esquemas pacticios, de suerte que puede surgir una auténtica Constitución sobre la base de la soberanía del Pueblo federal. Cfr. RUIPEREZ, J., Proceso constituyente, soberanía y autodeterminación, Madrid, 2003, pp. 135 y ss. 
conjugar intereses diversos y acometer unos fines a corto plazo. La adaptabilidad constituye precisamente el signo distintivo de este proyecto que busca, mediante nuevas fórmulas de carácter abierto y evolutivo, encontrar su culminación

Por otra parte, transponiendo los términos propios de la Teoría de la Constitución, una parte de la doctrina señala que el cuerpo normativo formado por los Tratados fundacionales presenta los caracteres de una Constitución rígida. Afirmación que basan en el análisis de los procedimientos contenidos en los propios Textos básicos de las Comunidades y de la Unión para modificar el Derecho originario. Debido al hecho de que tales procedimientos presentan un carácter más agravado que el previsto para adoptar los actos que integran el Derecho Comunitario derivado, aludirán a la existencia de una rigidez formal apuntando la idea de que es posible hablar de una Constitución en sentido formal en sede europea ${ }^{14}$. Con este enfoque, harán especial hincapié en la diferencia que hay entre los Tratados comunitarios y los de Derecho Internacional clásico en razón del diferente modo de proceder a la revisión de unos u otros, con el objeto de apuntalar sobre esta distinción la autonomía del ordenamiento jurídico comunitario respecto al Derecho Internacional general, dentro del marco del llamado proceso de constitucionalización de los Tratados comunitarios aludido.

Además, como quiera que, una vez aprobadas según los procedimientos formales previstos, todas las modificaciones se integran en el Derecho Comunitario primario con el mismo rango y valor que los Tratados fundadores, parte de la comunidad científica ve en las reformas un método para crear nuevo Derecho Comunitario de rango constitucional y lograr avanzar, por este mecanismo, en la consolidación de una auténtica Constitución Europea.

Sin embargo, en relación con el tema objeto de este estudio, destaca la necesidad del consentimiento unánime de todos los Estados miembros de la Unión para proceder a revisar formalmente el Derecho Comunitario originario. De este dato, se ha de colegir que los Estados ostentan, al menos colectivamente, el poder de decisión final sobre la revisión de los Tratados fundacionales, y que cada uno de ellos puede, individualmente, impedir cualquier modificación. En este aspecto, siguen firmemente anclados a su base internacional. Aunque también intervienen en este proceso de reforma las Instituciones comunitarias, esto no empece a la anterior afirmación, como se verá seguidamente. Realmente, para determinar la verdadera naturaleza de la Unión Europea, el análisis de la revisión de sus Normas Fundamentales proporciona datos de inestimable valor.

\section{LOS PROCEDIMIENTOS DE REVISIÓN PREVISTOS EN LOS TRATADOS ORIGINARIOS.}

Aunque los Estados no reconocen expresamente su deseo de sustraer los Tratados constitutivos a las reglas generales que rigen para los Tratados Internacionales en esta materia, han previsto, a lo largo de su articulado, procesos específicos para reformar el contenido de las normas constitutivas de la nueva entidad que crean. Procedimientos que presentan algunas características especiales respecto al modo usual de proceder para modificar los Tratados Internacionales multilaterales.

Desde el inicio del proceso de integración comunitario, con la firma de los Tratados 
Constitución Europea, siquiera parcial, cada vez más desligada del ordenamiento jurídico internacional y más próxima a un Derecho interno.

En fin, resulta evidente que se impone analizar el procedimiento de revisión previsto en el TUE para determinar su naturaleza y alcance.

En este análisis destaca la existencia de tres fases diferenciadas y consecutivas que han de ser franqueadas para culminar la revisión formal de los Tratados: una propiamente comunitaria, otra de carácter diplomático, y por último, una fase nacional.

1. La fase comunitaria del procedimiento general de revisión. La iniciativa de revisión puede partir de la Comisión o del Gobierno de cualquiera de los Estados miembros, los cuales pueden presentar al Consejo proyectos de reforma de los Tratados. A continuación, este órgano comunitario ha de proceder a consultar sobre esta propuesta al Parlamento Europeo y, en su caso, a la Comisión. Evacuadas estas consultas, compete al Consejo pronunciarse sobre la perspectiva de reforma. Si la considera necesaria, por mayoría de sus miembros ${ }^{17}$, emitirá un dictamen favorable a la constitución de una Conferencia de los representantes de los gobiernos de los Estados miembros, procediendo el Presidente del Consejo a su convocatoria formal.

Del examen de esta primera etapa, se observa que se produce una participación de los Estados miembros que se puede realizar en dos momentos distintos. En primer lugar, los Estados miembros ostentan el derecho a formular propuestas de revisión cuando estimen que una modificación es necesaria. En segundo término, los Estados intervienen en la adopción de la decisión del Consejo de convocar la Conferencia intergubernamental.

Pero la mayor peculiaridad de esta fase del proceso de revisión radica en la intervención obligatoria de las Instituciones comunitarias. Aunque la participación de la Comisión y del Parlamento Europeo es modesta, resulta indudable que es una Institución comunitaria, el Consejo, la que determina, en última instancia, la viabilidad de la propuesta de revisión y quien decide sobre la continuación o no del proceso. Ahora bien, a nadie se le oculta que el Consejo difícilmente podría impedir o impulsar la actividad reformadora sin contar con la voluntad de los Estados, ya que son, en el fondo, los representantes de los Gobiernos de los Estados miembros los que componen esta Institución y, por tanto, los que se van a pronunciar sobre la apertura o no del proceso reformador ${ }^{18}$

2. La Conferencia de los representantes de los Gobiernos de los Estados miembros dentro del proceso de revisión. Finalizada la fase comunitaria se abre la etapa intergubernamental que se desarrolla en el seno de la Conferencia convocada. Conferencia que se presenta como el órgano en el cual los Estados miembros determinan la forma, el alcance y el contenido propio de la revisión. Su duración puede ser bastante prolongada dependiendo del volumen de las cuestiones a tratar y de la dificultad que exista para llegar a un acuerdo entre los Estados. En relación a su funcionamiento y a su composición, presenta un carácter propiamente diplomático, pues son los Ministros de Asuntos Exteriores y los Embajadores permanentes ante la Unión Europea de cada uno de los Estados miembros quienes debaten las distintas cuestiones, adoptando, de común acuerdo y artículo por artículo, las modificaciones a introducir. Resulta meridiano que se trata de una fase marcada por la preponderancia de los Estados miembros en la que reina la regla de la unanimidad, siendo éstos los que determinan el contenido y alcance de la revisión mediante un procedimiento típico de Derecho Internacional.

3.- La entrada en vigor del Tratado de revisión. Concluidos los trabajos en el seno de 
«El Gobierno de cualquier Estado miembro o la Comisión, podrá presentar al Consejo proyectos de revisión de los Tratados sobre los que se funda la Unión./ Si el Consejo, previa consulta al Parlamento Europeo y, en su caso, a la Comisión, emite un dictamen favorable a la reunión de una conferencia de los representantes de los Gobiernos de los Estados miembros, ésta será convocada por el presidente del Consejo, con el fin de que se aprueban de común acuerdo las modificaciones que deban introducirse en dichos Tratados. En el caso de modificaciones institucionales en el ámbito monetario, se consultará también al Consejo del Banco Central Europeo./ Las enmiendas entrarán en vigor después de haber sido ratificadas por todos los Estados miembros, de conformidad, con sus respectivas normas constitucionales.»

Tras la entrada en vigor del Tratado de Amsterdam, éste artículo es el número 48 del TUE, en el cual, lógicamente, ya no aparece la previsión que se contenía en su segundo apartado relativa a la convocatoria de una Conferencia Intergubernamental en 1996 con el fin de proceder a la reforma de aquellos puntos que así se preveían en los Tratados.

La unificación efectuada obedece al propósito de acometer las modificaciones futuras con un carácter unitario, esto es, englobando tanto los pilares comunitarios como los intergubernamentales, acentuando así la concepción unitaria de la Unión.

Pero de la comparación entre esta disposición con lo previsto en los artículos respectivos anteriores en cada uno de los Tratados a los que sustituye, se observa que apenas se producen cambios. Las únicas modificaciones son la lógica alineación del procedimiento previsto para la revisión en el TCECA y la consulta al Banco Central Europeo para llevar a cabo cambios institucionales en materias monetarias.

Con esta previsión y las que la antecedieron se establece un procedimiento distinto para la reforma de los Tratados comunitarios frente al principio general de libertad de formas que rige la modificación de los Tratados Internacionales en general. Principio que predica que los Estados pueden convenir libremente los cambios que estimen oportunos siempre que consientan a los mismos unánimemente y manifiesten esa voluntad a través de un instrumento jurídico del mismo tipo ${ }^{15}$. Si a esto se le añade la ausencia de cláusula de retirada ${ }^{16}$ en los Tratados comunitarios, y la alusión específica a la duración ilimitada de la Unión, una parte importante de la doctrina argumenta a favor de la naturaleza específica de estos Tratados, sosteniendo que aunque su conclusión y entrada en vigor originaria se desarrolló dentro del marco del Derecho Internacional Convencional, su evolución posterior trasciende este origen. Por ello, sostienen que tales Textos se presentan como

15 Cfr. MARTINEZ CUADRADO, M., «La revisión de los Tratados y el Poder Constituyente de la Unión Europea», en OREJA AGUIRRE, M. (Dir.), y FONSECA MORILLO, F.(coord.), El Tratado de Amsterdam. Análisis y comentarios., Madrid, 1998, vol. I, p. 52; CAMPIS ERITJA, M., «La revisión del Tratado de la Unión Europea», Gaceta Jurídica de la Comunidad Europea y de la Competencia, Serie D, D-24, 1995, pp. 7-80.

16 Nótese que, sin embargo, el Tratado Constitucional, ha incluido en su art. I-60 la previsión de la retirada voluntaria de un Estado de la Unión, que habrá de adoptarse conforme sus normas constitucionales para proceder seguidamente a negociarse entre la Unión y ese Estado un acuerdo que regule la forma de su retirada. Llama la atención que en nombre de la Unión celebrará ese acuerdo el Consejo de ministros por mayoría cualificada. En suma, es más fácil retirarse de la Unión que adoptar una reforma, constituyendo esta posibilidad una seria amenaza a esgrimir en las negociaciones conducentes a una reforma. Extremo que se reflejó por bastantes miembros de la Convención durante su elaboración. 
En definitiva, la remisión a las normas constitucionales propias de cada Estado para ratificar los Tratados de revisión abre los siguientes problemas: el reconocimiento o no de un poder de integración constitucional y sus límites desde la propia Teoría de la Constitución; la exigencia del respeto a la voluntad popular inherente a un sistema democrático, y el control previo de la constitucionalidad del Tratado de revisión previsto en algunos de los sistemas constitucionales de los Estados miembro.

Pero lo que interesa aquí es el papel determinante que se les reserva a los Estados en la reforma y, en particular, la necesidad de su consentimiento unánime para que ésta se lleve efectivamente a cabo. Aunque existe una participación de las Instituciones comunitarias en el procedimiento de reforma, lo cierto es que la decisión última sigue correspondiendo a los Estados, y, además, esto se manifiesta en todas las fases del procedimiento, a saber, en el seno del Consejo, en el curso de la Conferencia intergubernamental, y, por último y con especial relevancia, en la necesidad de que presten su conformidad de forma expresa y de acuerdo con sus previsiones constitucionales. A la vista de cuanto se ha dicho se colige que el poder de revisión pertenece a los Estados que de este modo son dueños de decidir el destino de la «Constitución» comunitaria.

Por otra parte, hay que señalar que el procedimiento dispuesto en el artículo que se acaba de reproducir no es la única vía existente para enmendar los Tratados fundacionales. Existen además un conjunto de estipulaciones en los Tratados comunitarios que regulan otros procedimientos de reforma. No obstante, se trata de supuestos muy específicos, diseñados para realizar cambios en previsiones concretas del Derecho originario y cuya presencia atestigua el marcado carácter dinámico de la construcción comunitaria. Desde una óptica procedimental, se caracterizan por entrañar una simplificación respecto del mecanismo ordinario de revisión. En todo caso, se trata de supuestos excepcionales en los que esta capacidad aparece estrechamente circunscrita por constituir excepciones a la regla general que regula las modificaciones de las normas fundamentales de las Comunidades y de la Unión. Consecuentemente, la revisión con intervención única de las Instituciones comunitarias se configura necesariamente con carácter restrictivo, ya que si no se abría franqueado un paso definitivo en la naturaleza de la Unión que podría decidir soberanamente sobre su destino. Ni que decir tiene que, en tal supuesto, la soberanía estatal no existiría y que el Poder Constituyente residiría en la nueva entidad. El ejemplo más relevante de modificación autónoma se encontraba en el artículo 95.3 y 4 del TCECA. Era un procedimiento complejo que involucraba a todas las Instituciones comu-

17 Aunque en el artículo 48 del TUE no se indica la mayoría necesaria para adoptar tal decisión, se infiere que este acuerdo sigue el sistema general de adopción de decisiones previsto en el TUE. Vid. DIEZHOCHLEITNER, J., y MARTINEZ CAPDEVILA, C., Derecho Comunitario europeo. Tratados y otros textos anotados. Jurisprudencia básica del Tribunal de Justicia de las Comunidades Europeas, Madrid, 1996, pp. 156-158.

18 Aspecto que resaltan LOUIS, J.V., «Quelques considérations sur la révision des Traités instituant les Communautés», Cahiers de Droit Européen, 1980, n. 5-6, pp. 553-554; DEGLIEGE-DEQUARIS, M., «Révision des Traités européens en dehors des procédures prévues», Cabiers de Droit Européen, 1980, nº. 5-6, p. 539; CAMPIS ERITJA, M., «La revisión del Tratado...», cit., p. 17. Por contra, DA CRUZ VILAÇA, J.L., y PIÇARRA, N., «Y a-t-il des limites materièlles a la revisión des Traités instituant les Communautés Européennes?», Cabiers de Droit Européen, $\mathrm{n}^{\circ} .1$ y 2, 1993, p. 5, opinan que el papel del Consejo es determinante y que hay que considerar que es una Institución comunitaria y no el representante del interés exclusivo de los Estados. 
la Conferencia, se abre la etapa propiamente nacional, que se sustancia en el interior de cada uno de los Estados conforme a las previsiones contenidas en sus Constituciones sobre la ratificación de los Tratados Internacionales de integración. En efecto, el texto de la modificación sólo puede entrar en vigor tras su ratificación por todos y cada uno de los Estados siguiendo el procedimiento constitucional respectivo previsto para consentir definitivamente en obligarse por el Texto del Tratado de revisión ${ }^{19}$

Conforme señala M. Campis Eritja, «la exigencia de ratificación significa que el derecho final a la conclusión del tratado de revisión se sigue reservando a los Estados miembros, lo que dificulta una constitucionalización completa del Derecho originario y refuerza el carácter jurídico de las Comunidades Europeas en tanto que Organización Internacional. Queda claro que la fuente de la obligación convencional que en su caso pueda establecer el Tratado de la Unión revisado sigue siendo la voluntad soberana de cada uno de los Estados miembros. Además, los efectos de la revisión no se producen hasta que todos y cada uno de los Estados miembros han prestado su consentimiento en quedar obligados por el Tratado» ${ }^{20}$. Y los mecanismos y forma de conformar y expresar esa voluntad estatal han de realizarse conforme a las normas constitucionales al efecto contenidas en sus Constituciones. La razón de este proceder radica en que es a través de este mecanismo como se garantiza en todos y cada uno de los Estados miembros que se dé la participación democrática necesaria para ratificar el texto de la revisión.

Este sistema de entrada en vigor de la modificación origina numerosos problemas habida cuenta del riesgo que existe de un rechazo al Tratado de revisión que puede provenir de cualquiera de los Estados, ya sea a través de un veto de sus Parlamentos, bien de un rehúse de sus propios nacionales si se celebra un referéndum y su resultado es negativo ${ }^{21}$, o derivado del pronunciamiento de los jueces de la constitucionalidad que estimen que ese Tratado es contrario a la Constitución (como, por ejemplo, sucedió en Francia y en España para ratificar el TUE). En fin, las razones de la no aceptación de la revisión en la fase propiamente estatal pueden ser muy diversas. En el fondo, esto nada tiene de extraño puesto que la enmienda acordada suele afectar materialmente a lo establecido en las propias Constituciones nacionales, lo cual lógicamente suscita importantes problemas constitucionales.

19 Se trata de la problemática de la naturaleza de estos instrumentos y del procedimiento a seguir para su inserción en el Derecho interno. Al respecto, el Tribunal Constitucional español en su Dictamen de 1 de julio de 1992, indica que le son aplicables las reglas contenidas en los arts. 94 a 96 de la Constitución previstas para los Tratados Internacionales en general, ya que considera que mientras tales Tratados no hayan sido ratificados por todos los Estados miembros, no son todavía Derecho Comunitario sino Derecho Internacional convencional, que necesitan, en primer lugar, su ratificación conforme el régimen previsto en la Constitución para realizar tal operación. Por ello, no podrán ser ratificados en el caso de que contengan estipulaciones contrarias a la Constitución sin que medie una previa revisión constitucional que haga desaparecer esa contradicción, según lo previsto en el art. 95.1 que les es plenamente aplicable. Además se requiere su publicación íntegra en el B.O.E.

20 CAMPIS ERITJA, M., «La revisión del Tratado...», cit., p. 60.

21 Este problema ya se ha manifestado en el proceso de ratificación y entrada en vigor del TUE a raíz del rechazo de Dinamarca, situación que fue subsanada, a la postre, mediante unos compromisos especiales y un régimen particular de exenciones para ese país, que recibieron la crítica de gran parte de la doctrina por su carácter apócrifo y contrario al principio de igualdad y del propio espíritu de integración. Nuevamente con la ratificación del Tratado de Niza, debido a la negativa del pueblo irlandés en el referéndum de 7 de junio de 2001 que condujo a un nuevo referéndum el 19.10.2002 esta vez con resultado positivo. 


\section{TRATADOS CONSTITUTIVOS.}

Además de los problemas que se pueden suscitar en la fase estatal de ratificación de las reformas, cobra una especial relevancia el alejamiento del procedimiento de los ciudadanos. Circunstancia que se ha puesto sobre todo de manifiesto a partir de los problemas suscitados para ratificar el Tratado de Maastricht. Desde entonces, se buscan soluciones para paliar este fenómeno, que se suelen encaminar hacia la búsqueda de una implicación del mayor número posible de actores en el proceso de reforma, al mismo tiempo que se busca un consenso entre las distintas fuerzas políticas nacionales en torno a las reformas a introducir, y se incide en procurar una mayor información y acercamiento a los nacionales de los distintos Estados. Con todo ello se pretende salir al paso de los principales inconvenientes que provoca el indudable predominio intergubernamental del procedimiento de modificación, que proyecta consecuencias nocivas sobre la legitimidad democrática indispensable para acometer objetivos ambiciosos y suscitar un sentimiento de lealtad hacia la Unión entre los ciudadanos de los Estados miembros

23 .

A todo lo anterior hay que añadir las consecuencias que el mantenimiento de un sistema de este tipo suscita ante la ampliación de la Unión. Si ya resultaba difícil llevar a cabo una reforma de los Tratados en aspectos básicos, esta situación se torna más complicada en una Unión cada vez más extensa. En efecto, si el proyecto europeo es un proceso especialmente dinámico que se forja mediante conquistas concretas que se alcanzan tras arduas negociaciones y a través de compromisos cruzados, resulta meridiano que para seguir avanzando hacia una mayor profundización entre todos los Estados miembros, el requisito de la unanimidad constituye un obstáculo prácticamente insalvable. Si esto ha sido posible, y no sin problemas, hasta el momento, sin embargo difícilmente puede seguir dando frutos en una integración de ya 25, pronto probablemente 27 o incluso más Estados.

En el fondo, toda esta historia no hace más que resaltar el carácter inacabado y dinámico de la construcción europea. Sin embargo, no se puede dejar de observar que la indefinición permanente no puede suscitar un sentimiento de lealtad ni suplir las funciones fundamentales que los Estados Constitucionales siguen teniendo encomendadas en nuestro tiempo.

\section{OTRAS PROPUESTAS EN LA HISTORIA COMUNITARIA.}

En realidad, la necesidad de superar el requisito del consentimiento unánime de todos los Estados para modificar los Tratados ya se ha planteado en distintas ocasiones a lo largo de la historia de la Comunidad.

La mayor innovación al respecto se encuentra en el Proyecto de Constitución Europea aprobado por el Parlamento Europeo el 10 de febrero de 1994. En esta propuesta, al racionalizar el sistema de fuentes en su artículo 31, se establecen las Leyes constitucionales, que son aquéllas que tienen por objeto modificar o completar la Constitución. Tales leyes se aprueban por mayoría de $2 / 3$ de los miembros que integran el Parlamento Europeo y por el Consejo por mayoría supercualificada ${ }^{24}$. Mayoría supercualificada que se define de manera muy compleja y en sentido negativo en el artículo 20, al disponer que «La mayoría supercualificada no se alcanzará en caso de que se oponga un cuarto, como mínimo, de los 
nitarias y que dadas las precauciones y requisitos exigidos apenas se utilizó en la práctica ${ }^{22}$. En el resto de los supuestos de revisión especial, hay que tener en cuenta que siempre se exige unanimidad en el Consejo.

A las modificaciones expuestas hay que añadir las adaptaciones derivadas de la adhesión de nuevos Estados a la Unión que son el resultado de la vocación abierta que presenta el proyecto europeo desde su inicio, formulada expresamente ya en el Preámbulo del TCEE. El TUE unifica los diversos procedimientos existentes en los Tratados comunitarios al respecto, estableciendo en su artículo 49 que el Estado solicitante dirigirá una petición de adhesión al Consejo, que decidirá por unanimidad, previa consulta a la Comisión y previo dictamen conforme del Parlamento Europeo, el cual ha de pronunciarse por mayoría absoluta de los miembros que lo componen. Las condiciones de la admisión y adaptaciones necesarias de los Tratados por la nueva incorporación serán objeto de un acuerdo entre los Estados miembros y el Estado solicitante, es el Tratado de adhesión, el cual será sometido a la ratificación por todos los Estados de acuerdo con sus normas constitucionales respectivas. Nuevamente nos encontramos con la exigencia de la unanimidad y con la remisión a lo previsto en las Constituciones nacionales para ratificar Tratados.

Anteriormente se puso de manifiesto la existencia de sustanciales diferencias entre la revisión de una Constitución en sentido propio, sea ésta de un Estado unitario o de un Estado federal, de la modificación de la norma fundamental de una Confederación. En el primer caso, y respecto al Estado federal, se ha observado como el poder de enmienda de la Constitución federal en ningún caso queda al libre albedrío de los Estados federados. Lejos de eso, la reforma se presenta como un acto del propio Estado federal en su conjunto y la participación de los miembros en el proceso de enmienda obedece al propósito de garantizar la subsistencia de la autonomía de las entidades político-territoriales al mismo tiempo que lograr su integración en el conjunto del sistema. Al contrario, en una Confederación el procedimiento a seguir para llevar a cabo una reforma del vínculo asociativo aparece condicionado por su naturaleza contractual. Por lo tanto, al igual que en Derecho Internacional general, lo indispensable en este caso es el consentimiento unánime de todos los Estados para proceder a su modificación.

A la vista de estas consideraciones y de lo expuesto sobre el procedimiento de reforma de los Tratados comunitarios, se entiende fácilmente que sea lugar común entre la doctrina afirmar que el poder de revisión pertenece a los Estados miembros de la Unión en su estadio actual. Y aunque una parte de los autores resaltan la participación de las instituciones comunitarias, ello en nada afecta a que los Estado siguen siendo realmente los «Amos de los Tratados». Desde esta perspectiva, sin duda la Unión Europea hoy constituye una Confederación.

\section{PRoblemas QUe Plantea TAL SISTEMA DE MODIFICACiÓN DE LOS}

22 Se precisaba una proposición de revisión que había de ser aprobada de común acuerdo por la Comisión y el Consejo, decidiendo este último por una mayoría que ha de comprender al menos a doce de sus miembros. A continuación, se exigía dictamen del Tribunal de Justicia comunitario sobre si tal propuesta es conforme con el supuesto regulado en el artículo 95. Finalmente, necesitaba el voto favorable emitido por el Parlamento Europeo por mayoría de tres cuartos de los votos expresados y de dos tercios de sus miembros. 
pero que supone una desnaturalización del proyecto integrador igualitario planteado desde el principio ${ }^{29}$

Nada tiene de extraño pues que periódicamente se abogue por encontrar nuevas soluciones al sistema de reforma de los Tratados que han dado lugar a numerosos estudios y propuestas sobre este tema ${ }^{30}$. A este efecto, veremos cómo se ha planteado y cuál es el resultado en el texto aprobado por la Convención e igualmente tras la GIG que ha continuado el proceso.

\section{EL PROCEDIMIENTO DE REFORMA EN EL PROYECTO DE TRATADO POR EL QUE SE INSTITUYE UNA CONSTITUCION PARA EUROPA.}

En la CIG 2000 que dio lugar al Tratado de Niza, se fue más consciente que nunca de los problemas de alcanzar acuerdos unánimes entre los Estados para modificar los Tratados comunitarios. Las complejidades y dificultades que se han manifestado en la génesis de tal Tratado — Consejo Europeo de Niza en diciembre de 2000 - y en su posterior ratificación por los Estados miembros, ponen de relieve la gran dificultad de seguir avanzando a través de tal sistema de reforma en la Europa ampliada. Extremo que ha quedado asimismo patente en la última GIG.

Más allá de esto, y en general, se toma conciencia de la necesidad de plantearse y resolver algunos de los principales problemas que se presentan en el devenir de la Unión Europea. La «Declaración relativa al futuro de Europa» - $\mathrm{n}^{\circ} 23$ - anexa a este Tratado denota esta percepción, apelando a la apertura de un debate más amplio y profundo sobre el futuro de la Unión Europea, en el que ha de intentarse implicar a los Parlamentos nacionales, a la sociedad y a los Estados candidatos. Se precisa que en este debate se han de abordar, en particular, las siguientes cuestiones: 1. El establecimiento de una delimitación más precisa de las competencias entre la Unión y los Estados miembros; 2. El estatuto de la CDF; 3. La simplificación de los Tratados para que sean más claros y fáciles de comprender, sin cambiar su sentido; 4. La determinación de la función de los Parlamentos nacionales en la arquitectura europea.

Con este objetivo se contemplan tres fases. En 2001, las Presidencias sueca y belga, en cooperación con la Comisión y el Parlamento Europeo, fomentarán un amplio debate en el que se asociarán a los parlamentos nacionales y a la opinión pública. En la reunión del Consejo Europeo de Laeken de diciembre de 2001 habrá de aprobarse una declaración en que se precisen las iniciativas adecuadas para llevar a cabo tal proceso durante los años 2002 y 2003. Finalmente, se convocará una nueva Conferencia de los

23 El proceso de reforma que ha conducido al Tratado de Ámsterdam ha tomado un rumbo distinto para hacer frente a la crítica de que la integración europea es un proceso de integración por elites. Cfr. MARTINEZ CUADRADO, M., «La revisión de los Tratados y...», cit., p. 65. Pero en Niza se volvió al error de la opacidad, error que se reproduce en la última CIG pese a la fase anterior de la Convención. 
Estados miembros que represente, al menos un octavo de la población de la Unión o un octavo de los Estados miembros que representen, como mínimo, un cuarto de la población de la Unión» ${ }^{25}$.

Como expresa A. Perez Calvo, «aquí nos encontramos ya con un instrumento que, una vez aprobado por los Estados integrantes de la Unión Europea de acuerdo con los sistemas internacionales tradicionales ya no va a exigir la unanimidad para su posible reforma, por lo que entra dentro de lo que podemos denominar una Constitución federal. La intensidad del carácter federal o, si se prefiere, de la integración será mayor o menor, pero se ha roto la regla de la unanimidad $\rangle^{26}$.

También ante la CIG-96 para la revisión de los Tratados — que dará lugar al Tratado de Ámsterdam—, se planteó, por parte de algunos sectores, la conveniencia de que la entrada en vigor de la revisión se pudiese llevar a cabo de otra forma que no fuese la unanimidad, proponiéndose distintas fórmulas en las que se combinaban la ratificación por una mayoría de Estados y una mayoría del conjunto de sus poblaciones en proporciones variables ${ }^{27}$. En el Informe del Grupo de reflexión de $1995^{28}$ preparatorio para la CIG, se alude escasamente al tema en su punto 99, indicando que existe un amplio consenso en el grupo para mantener la unanimidad en las decisiones de Derecho Primario más la ratificación de los Parlamentos nacionales. Aunque se indica que algunos miembros manifestaron su preocupación porque tal sistema podía provocar la parálisis en una Unión ampliada, las propuestas que efectuaron se dirigían a prever simplemente que algunas disposiciones del Tratado fuesen más fácilmente modificables, a través de la unanimidad en el Consejo, con posibilidad de establecerse para las mismas un sistema más ágil posteriormente, o a través de un procedimiento simplificado. En fin, nada nuevo pues esta posibilidad ya se establecía en el TUE, y como veremos, también se recoge en el proyecto de la Convención, confirmándose y ampliándose tras la CIG.

Como quiera que las distintas propuestas planteadas no han tenido éxito, se mantiene el mismo sistema. Ante tales circunstancias, que ponen de manifiesto la imposibilidad práctica de poner de acuerdo a todos los Estados participantes para acometer objetivos más amplios y ambiciosos en el futuro, el único intento de solución que ha tenido concreción positiva ha sido el establecimiento de la llamada «cooperación reforzada». Sistema cuyo fin es permitir que los Estados partidarios de alcanzar mayores cotas de integración afrontando objetivos más ambiciosos, puedan avanzar por ese camino,

24 Sobre la elaboración de este precepto, vid. MOLINA DEL POZO, F. (Dir.), Comentarios al proyecto de Constitución europea, Granada, 1996, pp. op. cit., pp. 298-300. En sus primeras versiones se requería en el Consejo unanimidad. Por otra parte, llama la atención que se previese un régimen transitorio de cinco años para tales leyes en el cual habían de adoptarse por unanimidad.

25 Nótese que en su art. 47 se preveía su entrada en vigor «cuando la mayoría de los Estados miembros que representen las cuatro quintas partes de la población la hayan ratificado. Los Estados miembros que no hayan podido presentar los instrumentos de ratificación en el plazo fijado deberán elegir entre abandonar la Unión y el mantenimiento de su permanencia a la Unión así modificada. En caso de que decidan abandonar la Unión, se celebrarán acuerdos particulares con el fin de otorgarles el estatuto de asociado privilegiado»

26 PEREZ CALVO, A., «Integración Europea y Constitución Europea», Civitas Europa, n. 4, 2000, p. 151.

27 Vid. estas alternativas en CAMPIS ERITJA, M., «La revisión del Tratado...», cit., p. 60, nota nº. 64.

28 Vid. este Informe en Gaceta Jurídica de la Unión Europea, Serie B, B-108, 1995, pp. 63-92. 
marzo de 2002 debiendo concluirlos en un año, tras lo cual se presentarán sus resultados al Consejo Europeo mediante un documento final en el que podrán bien comprenderse las diferentes opciones con expresión del apoyo que obtuvieron cada una, bien si se hubiese producido consenso bajo la forma de recomendaciones. Y establece su valor: este documento más el resultado de los diferentes debates nacionales servirán de punto de partida para los debates de la CIG 2004 que será la que decida. Además se prevé la constitución de un foro abierto a la participación de las organizaciones representativas de la sociedad civil.

Esta Convención que empezó sus trabajos el 28 de febrero de 2002 adoptó por consenso los días 13 de junio y 10 de julio de 2003 el Proyecto de Tratado por el que se instituye una Constitución para Europa, presentándolo al Presidente del Consejo Europeo en Roma el 18 de julio de $2003^{32}$. No obstante, según lo previsto, sólo la CIG siguiente podrá determinar realmente su contenido por común acuerdo de los representantes gubernamentales. CIG que convocó el Consejo y que comenzó el 4 de octubre del año 2003, confiándose, en un principio, en que acabase en diciembre con la finalidad de que el Tratado estuviese firmado antes de las elecciones al Parlamento Europeo de junio de 2004. Sin embargo, pronto empezaron en su seno las disensiones y bloqueos que estuvieron a punto de hacer fracasar cualquier posibilidad de acuerdo, el cual finalmente se alcanzó, bajo la Presidencia irlandesa, en el Consejo Europeo de 18 de junio de 2004, remitiéndose para el texto definitivo al trabajo de los servicios lingüísticos con la finalidad de firmar el Tratado a finales de octubre lo cual tuvo lugar el 29 de octubre de 2004. Acorde con el procedimiento normal, a continuación el texto del nuevo Tratado ha de ratificarse por todos y cada uno de los Estados miembros de conformidad con sus normas constitucionales, pues en este aspecto nada cambia ${ }^{33}$. Se abre, por tanto, un futuro incierto pues ha de producirse esa ratificación en 25 Estados que presentan previsiones diferentes para llevarla a cabo y muchos de los cuales han anunciado su intención de acudir al uso del referéndum ${ }^{34}$. Tal es el caso de España que ha realizado el 20 de febrero de 2005 un referéndum sobre este Tratado, primero que se celebra en España sobre la integración Europea y segundo

29 Cfr. MOLINA DEL POZO, F. (Dir.), Comentarios al proyecto de..., op. cit., pp. 437-438.

30 Vid. un comentario y exposición de algunos de los más relevantes en CRAIG, P., «Constitución, constitucionalismo y Unión Europea», pp. 255-263, en GARCIA DE ENTERRIA, E.(Dir.) y ALONSO GARCIA, R., (Subdir.), La encrucijada constitucional de la Unión Europea, Madrid, 2002. Destaca el Informe realizado por el Centro R. Schumann del IUE por encargo de la Comisión referido a la simplificación de los Tratados, que le presentó a ésta en mayo de 2000. En el mismo se opta por un Tratado básico corto que incluya los principios fundamentales, la CDF y los aspectos de alcance constitucional de la Unión, que iría acompañado de dos Protocolos sobre política exterior y de seguridad común, y sobre cooperación judicial y penal en materias penales. Tal Tratado sustituiría al TUE. Al lado de tal Tratado básico, subsistirían el TCE sin lo que se hubiese incluido en el primero y los Tratados CECA y EURATOM. En realidad, como señala CRAIG, se trataba de una mera simplificación, no de una verdadera Constitución. Para que fuese una Constitución haría falta que se estableciese su rango superior, normas especiales para su modificación, y un sistema de control por un tribunal para garantizar que se cumplen esas normas. Cuestiones que no se abordan en el Tratado básico que mantiene su modificación a través de una CIG por unanimidad seguida de ratificación por todos los Estados. El resto de Tratados con él relacionados, se modificarían por decisión del Consejo, a determinar si por unanimidad o mayoría cualificada, más aprobación del Parlamento Europeo. Este Informe resulta de interés por cuanto anticipa la tesis de la posibilidad de distintos sistemas de revisión que se reflejará después en la Declaración del Consejo de Laeken y que se plantea posteriormente por diversos miembros de la Convención en el curso de los debates al igual que en el seno de la CIG. 
Representantes de los Gobiernos de los Estados miembros en 2004 para tratar las cuestiones objeto de debate con miras a introducir las correspondientes reformas en los Tratados. Por otra parte, se advierte expresamente que la CIG 2004 no será condición previa a la ampliación y que se invitará a participar en la misma como observadores a los Estados que en esa fecha aún no hayan concluido las negociaciones de adhesión con la Unión.

Conforme estas previsiones, el Consejo Europeo de Laeken celebrado los días 14 y 15 de diciembre de 2001, adopta la «Declaración sobre el futuro de la Unión Europea» y decide convocar una Convención, siguiendo el precedente de la que redactó la CDF.

En esta Declaración, plena de interrogantes, se señala que actualmente la UE se encuentra en una encrucijada debido a su futura ampliación que exige formular propuestas para que sea más democrática, transparente y eficaz. Para ello manifiesta que debe lograrse acercar a los ciudadanos al proyecto europeo y a sus Instituciones, estructurar la vida política y el espacio político europeo en una unión ampliada, y hacer que la Unión se convierta en un factor de estabilidad en un mundo complejo y cambiante.

Para conseguirlo considera que se ha de dar respuesta a las siguientes cuestiones: cómo lograr un mejor reparto y definición de competencias en la UE, simplificar los instrumentos de la Unión, incrementar su democracia, transparencia y eficiencia, y abre el interrogante crucial de si todo ello no debe conducir a la adopción de un texto constitucional, de una Constitución para los ciudadanos de la Unión Europea.

Sobre este último extremo formula cuatro series de preguntas ${ }^{31}$. Al objeto que nos ocupa nos interesan, sobre todo, los interrogantes que plantea en la segunda serie sobre las cuestiones en torno a una posible reorganización de los Tratados. En este sentido, se plantea: ¿Debe hacerse una distinción entre un tratado básico y las demás disposiciones de los tratados, en su caso, mediante una separación de los textos? ¿Puede esto conducir a una distinción entre los procedimientos de modificación y de ratificación del tratado básico y las demás disposiciones de los tratados? E igualmente, la cuestión que suscita en la cuarta serie en torno «a si esta simplificación y redistribución no deberían conducir a plazo a la adopción de un texto constitucional», lo que conduce a plantearse cuáles debería ser sus elementos básicos, los valores de la Unión, los derechos fundamentales y deberes de los ciudadanos, y las relaciones de los Estados en el seno de la Unión.

Convoca una Convención para garantizar la participación más amplia posible en este debate, que tendrá como cometido examinar las cuestiones esenciales del futuro desarrollo de la Unión e investigar las distintas respuestas posibles. Fija su composición: un Presidente, dos Vicepresidentes, 15 representantes de los Jefes de Estado o de Gobierno de los Estados miembros, 30 miembros de los Parlamentos nacionales — dos por cada Estado-, 16 miembros del PE, y dos representantes de la Comisión. Los países candidatos participarán plenamente aunque no podrán impedir el consenso. El Praesidium, órgano directivo de la Convención, estará integrado por el Presidente y los dos Vicepresidentes, más 9 miembros - 3 de los Gobiernos que ostenten la Presidencia durante sus trabajos, 2 de los Parlamentos nacionales, 2 del PE, 2 de la Comisión-. En calidad de observadores se invitarán a 3 miembros del Comité Económico y Social, 3 de los interlocutores sociales europeos, 6 representantes del Comité de las Regiones — designados entre aquellas entidades subestatales que tengan competencias legislativas_- y el Defensor del pueblo.

Igualmente, determina su calendario y su método de trabajo: iniciará sus trabajos en 
el ámbito monetario, se consultará también al Banco Central Europeo. El Consejo Europeo podrá decidir por mayoría simple, previa aprobación del Parlamento Europeo, no convocar la Convención en caso de modificaciones cuya importancia no lo justifique. En este último caso, el Consejo Europeo establecerá un mandato para la Conferencia de los representantes de los Gobiernos de los Estados miembros.

La Convención examinará los proyectos de revisión y adoptará por consenso una recomendación a la Conferencia de los representantes de los gobiernos de los Estados miembros prevista en el apartado 3.

3. La Conferencia de los representantes de los Gobiernos de los Estados miembros será convocada por el Presidente del Consejo de Ministros, con el fin de que se aprueben de común acuerdo las modificaciones del Tratado por el que se instituye la Constitución.

Las enmiendas entrarán en vigor después de haber sido ratificadas por todos los Estados miembros, de conformidad con sus respectivas normas constitucionales.

4. Si, transcurrido un plazo de dos años desde la firme del Tratado por el que se instituye la Constitución, las cuatro quintas partes de los Estados miembros lo hubieran ratificado y uno o varios Estados miembros hubieran experimentado dificultades para proceder a dicha ratificación, el Consejo Europeo tomará conocimiento de la cuestión.» Seguidamente señaláremos qué novedades se introducen en este precepto respecto del sistema anterior. Pero previamente no se puede dejar de señalar que la Parte IV, donde está incluida esta disposición, fue una de las que más tardíamente abordó la Convención ${ }^{38}$, y se observa, tanto en el curso de los debates ${ }^{39}$, enmiendas planteadas ${ }^{40}$ y distintos textos que se sucedieron ${ }^{41}$, que pese a plantearse alternativas distintas ${ }^{42}$ —en concreto, bastantes convencionales plantearon la necesidad de superar la unanimidad para la revisión-, nunca hubo un propósito decidido de cambiar el régimen anterior en este sentido.

En cuanto a las modificaciones recogidas en este artículo nos encontramos:

Por un lado, en la fase de iniciativa se atribuye también el derecho para plantear la revisión al Parlamento Europeo ${ }^{43}$, y se prevé la notificación de la presentación de los proyectos de revisión a los Parlamentos nacionales de los Estados miembros.

Respecto a la adopción de la decisión de abrir el proceso de reforma, ésta se atribuye al Consejo Europeo —antes correspondía al Consejo de ministros_-, y se establece expresamente que esa decisión se adopte por mayoría simple.

A continuación se introduce la convocatoria de una Convención para preparar la CIG, institucionalizando la práctica seguida para elaborar la CDF y el PTICE. En este sentido, en cuanto a su composición, adopción por consenso y valor de sus trabajos, nada cambia respecto a la práctica anterior. Se prevé que se pueda prescindir de tal convocatoria si son modificaciones de menor importancia, extremo que decidirá el Consejo Europeo previa aprobación del Parlamento Europeo.

Finalmente, se encuentra la previsión contenida en su apartado 4, disponiendo que el Consejo Europeo tomará conocimiento si transcurridos dos años desde la firma del Tratado por el que se instituye la Constitución para Europa, uno o varios Estados miembros hubieran experimentado dificultades para ratificarlo, habiéndolo ratificado, sin

31 La primera relacionada con la simplificación de los Tratados sin cambiar su contenido. La tercera respecto a si la CDF debe integrarse en el Tratado básico y la pertinencia de la adhesión de la CE al CEDH. 
desde la entrada de la Constitución.

Aparte de no poder aventurar conjeturas sobre lo que deparará el futuro en esta fase por demás azarosa, lo cierto es que aun en el supuesto de que se consiguiese la ratificación del nuevo Tratado, no se acabarían los problemas, siendo el fundamental que sigue tratándose de un Tratado internacional, persistiendo el déficit democrático provocado, sobre todo, por el déficit de Constitución

No se puede dejar de hacer notar que en este contexto existe además una idea enraizada en un importante sector, tanto político como doctrinal, que parte de la creencia de que tanto la CDF como la hipotética y deseada Constitución Europea, son instrumentos para asentar la conciencia y el nacimiento de un pueblo europeo ${ }^{36}$. Con lo que constituirían, en realidad, la base para acometer un segundo objetivo de mayor calado y que no es otro que culminar la tarea de dotar a la UE de una Constitución ${ }^{37}$. Planteamientos en los que subyace que no existe aún una unidad previa, se base en un soporte cultural, nacional o de otro tipo, para construir la unidad política europea ya. Y que subsiste en el proyecto que emana de la Convención así como en el texto resultante de la CIG.

a) En la Convención.

Volviendo a la materia objeto de nuestro interés, el PTICE de la Convención recoge el procedimiento de revisión en su artículo IV-7, del siguiente tenor:

«1. El Gobierno de cualquier Estado miembro, el Parlamento Europeo o la Comisión podrán presentar al Consejo de Ministros proyectos de revisión del Tratado por el que se instituye la Constitución, que se notificará a los parlamentos nacionales de los Estados miembros.

2. Si el Consejo Europeo, previa consulta al Parlamento Europeo y a la Comisión, adopta por mayoría simple una decisión favorable al examen de las modificaciones propuestas, el Presidente del Consejo Europeo convocará una Convención compuesta por representantes de los parlamentos nacionales de los Estados miembros, del Parlamento Europeo y de la Comisión. En el caso de modificaciones institucionales en

32 El Prefacio, Preámbulo, las Partes I y II del PTICE junto con 3 Protocolos (Parlamentos nacionales, Subsidiaridad y proporcionalidad, representación de los ciudadanos en el Parlamento Europeo y ponderación de votos en el Consejo Europeo y en el Consejo de Ministros) más la Declaración aneja al Protocolo sobre representación de los ciudadanos en el Parlamento Europeo y ponderación de votos en el Consejo Europeo y en el Consejo de Ministros, habían sido presentadas previamente al Consejo Europeo de Salónica el 20 de junio de 2003. Las Partes III y IV, los Protocolos sobre el Grupo Euro y el que modifica el TEURATOM, y la Declaración sobre creación de un Servicio Europeo de Acción Exterior así como la Declaración al acta final de firma del TICE, se entregaron en el Consejo de Roma.

33 La norma sobre su entrada en vigor se recoge en el propio Tratado — art. IV - 447—, reproduciendo el sistema seguido hasta ahora para la entrada en vigor de las reformas. No obstante, nótese que existe una Declaración final anexa al Tratado que establece que si transcurridos dos años desde su firma el Tratado ha sido ratificado por al menos un $80 \%$ de los Estados, existiendo en varios o en uno de los que quedan dificultades para ello, se remitirá el asunto al Consejo Europeo. Enigmático en verdad que se pueda querer decir con ello, pero por las declaraciones de algunos participantes en la Convención, en cuyo texto ya se incluía esta referencia, parece que sería fundamental para adoptar cualquier tipo de decisión qué país o países no lo hubiesen ratificado transcurrido tal periodo.

34 Sobre las previsiones y dificultades para su ratificación en cada uno de los 25 Estados, cfr. CLOSA, C., «La ratificación de la Constitución de la UE: un campo de minas», (ARI -Análisis del Real Instituto Elcano), Boletin nº. 120/2004, 7 págs. 
oposición, el Consejo Europeo podrá adoptar la citada decisión./ Para la adopción de las decisiones europeas contempladas en los apartados 1 y 2, el Consejo Europeo se pronunciará por unanimidad, previa aprobación del Parlamento Europeo, que se pronunciará por mayoría de los miembros que lo componen».

Con ello en realidad la CIG, por un lado, procede a preservar la generalmente conocida como «cláusula pasarela» — antes ubicada en el artículo 24.4 de la Parte I en el texto de la Convención- bien que situándola certeramente en la Parte IV como un procedimiento de revisión simplificado ${ }^{47}$, a la vez que, por otro, introduce algunas modificaciones respecto a su regulación anterior. Se observa como en tal disposición se hace referencia a un doble supuesto: 1) posibilidad de que el Consejo se pronuncie en el futuro por mayoría cualificada en vez de por la unanimidad prevista en un ámbito o en un caso determinado de la Parte III; 2) posibilidad de que el Consejo adopte leyes o leyes marco de la Parte III por el procedimiento legislativo ordinario en lugar del procedimiento legislativo especial estipulado. Se cambia el orden de estas dos posibilidades respecto al anterior y se añade una limitación a la posible ampliación de la mayoría cualificada por cuanto se prevé que no se puede autorizar la adopción por mayoría cualificada de «decisiones que tengan repercusiones militares o en el ámbito de la defensa». Asimismo, en el apartado tercero, se contempla la remisión a los Parlamentos nacionales al Parlamento de cualquier iniciativa adoptada por el Consejo Europeo en ambos supuestos contemplados mientras que antes sólo se aludía a tal obligación para el caso de pretenderse sustituir la unanimidad por mayoría cualificada previéndose el transcurso de un plazo mínimo de cuatro meses desde tal transmisión al efecto de poder adoptar la decisión. Pero lo novedoso es que ahora se incluye la posibilidad de que cualquier Parlamento nacional se oponga a su uso notificándolo en un plazo de seis meses desde esa transmisión con la consecuencia de impedir su adopción. Esto otorga un poder de veto a los Estados miembros que puede dificultar en buena medida la utilización de las pasarelas previstas aunque también es cierto que supone una mayor democratización del sistema. Además en su último párrafo se requiere la previa aprobación del Parlamento Europeo que se pronunciará por mayoría de los diputados que lo componen lo cual supone un aumento de los poderes del Parlamento Europeo en los supuestos contemplados, puesto que antes la única

35 Cfr., en este sentido, por todos, RUIPEREZ, J.; La «Constitución Europea» y la ..., op. cit., pp. 137-138, pp. 150-151; FIGUERUELO, A., «La protección de los Derechos Fundamentales en el marco de la Unión Europea», Anuario de la Facultad de Derecho de la Universidad de la Coruña, no. 5, 2001, p. 339.

36 Cfr. ALDECOA LUZARRAGA, F., «El Tratado de Niza, consolidación y reforma de la Unión Europea», Cuadernos Europeos de Deusto, nº. 25, 2001, pp. 51-54; CARRILLO SALCEDO, J.A., «Notas sobre el significado político y jurídico de la Carta de Derechos Fundamentales de la Unión Europea», Revista de Derecho Comunitario Español, n. 9, 2001, pp. 7-26; RODRIGUEZ BEREIJO, A., «El valor jurídico de la Carta de los Derechos Fundamentales de la Unión Europea después del Tratado de Niza», pp. 203-205, p. 214, en GARCIA DE ENTERRIA, E., (Dir.) y ALONSO GARCIA, R., (Subdir.), La encrucijada constitucional de la Unión Europea, Madrid, 2002.

37 Como ponen de manifiesto MARSAL, M., «Objetivos y génesis de la Carta de Derechos Fundamentales de la Unión Europea», Autonomies, nº. 27, 2001, pp. 38-40, y RUBIO LLORENTE, F., «La Carta Europea de los Derechos», Claves de razón práctica, no. 122, 2002, p. 4, pp. 7-8. Aunque este último cuestiona críticamente que la CDF sea útil para alcanzar esa finalidad, la cual, por otro lado no le parece el mejor remedio para lograr reforzar la Unión, pp. 10-11. 
embargo, las cuatro quintas partes de los Estados miembros. Ciertamente no se sabe qué efectos jurídicos puede deparar en el futuro una expresión tan enigmática ${ }^{44}$.

b) En la CIG

A su vez, en la versión final del Tratado por el que se establece una Constitución para Europa, resultado de la CIG, se introducen cambios en la revisión ${ }^{45}$.

Así, se mantiene lo previsto en el artículo IV-7 anterior, que pasa a ser el IV-443 referente al procedimiento de revisión general con alguna pequeña adición y ligeros cambios de redacción o de orden, especificándose que se trata del proceso de revisión ordinario ${ }^{46}$.

Aparece como artículo IV-444 el que se denomina «Procedimiento de revisión simplificado», que establece : «1. Cuando la Parte III disponga que el Consejo se pronuncie por unanimidad en un ámbito o en un caso determinado, el Consejo Europeo podrá adoptar una decisión europea que autorice al Consejo a pronunciarse por mayoría cualificada en dicho ámbito o en dicho caso./ El presente apartado no se aplicará a las decisiones que tengan repercusiones militares o en el ámbito de la defensa./ 2. Cuando la Parte III disponga que el Consejo adopte leyes o leyes marco europeas por un procedimiento legislativo especial, el Consejo Europeo podrá adoptar una decisión europea que autorice a adoptar dichas leyes o leyes marco europeas por el procedimiento legislativo ordinario./ 3. Cualquier iniciativa tomada por el Consejo Europeo en virtud de los apartados 1 ó 2 se transmitirá a los Parlamentos nacionales. En caso de oposición de un Parlamento nacional notificada en un plazo de seis meses a partir de esta transmisión, no se adoptará la decisión europea contemplada en los apartados 1 ó 2. A falta de

38 En principio, en el esquema de anteproyecto de Tratado Constitucional elaborado por el Praesidium, que presentó en la sesión plenaria de 28 de octubre de 2002, la estructura que se propone es diferente al resultado final. En este anteproyecto se distinguían tres partes. La Primera dedicada a la arquitectura constitucional, en la cual se incluía la CDF. La Segunda abarcaría las políticas y acciones de la Unión. La Tercera contendría las disposiciones Generales y Finales. Mientras la Parte I ya aparece en este esbozo bastante definida, las otras dos restantes constituyen un somero bosquejo. Respecto a la última parte, se prevé un último Título que comprenda siete artículos relativos, respectivamente, a la derogación de los anteriores Tratados y continuidad jurídica respecto a la Comunidad Europea y Unión Europea; ámbito de aplicación del Tratado; valor de los Protocolos anexos; procedimiento de revisión del Tratado Constitucional; adopción, ratificación y entrada en vigor del Tratado Constitucional; duración; y lenguas. Tal estructura y el contenido previsto es bastante similar al resultante, bien que finalmente tal Parte pasa a constituir la Parte IV en la cual se incluye un artículo relativo a los símbolos de la Unión y otro dedicado a las Uniones Regionales, a la vez que se desglosa en dos artículos diferentes las materias relativas a la derogación de los Tratados anteriores y la previsión de la continuidad jurídica respecto de la CE y de la UE. Realmente la atención sobre la Parte relativa a las Disposiciones Generales y Finales empieza a partir de abril de 2003. Así, en la sesión plenaria de 24 y 25 de este mes se presenta el proyecto de artículo relativo a tal cuestión. El Vicepresidente Amato expresa que el procedimiento de revisión que se recoge en el en aquel entonces art. F de la Parte III, es el mismo que el previsto en los Tratados actuales por no haberse aún debatido sobre esta materia. A partir de entonces empiezan las propuestas, debates, enmiendas y modificaciones relativos a esta materia, que pasará a constituir en un paso posterior el artículo IV-6 de la Parte IV, para quedar finalmente como artículo IV-7. Es de destacar que el Presidente del Praesidium, en esa misma sesión, informa a la Convención que el Consejo Europeo de Atenas de 16 de abril confirmó que los resultados de la Convención debían presentarse en el próximo Consejo Europeo a celebrar el 20 de junio en Salónica. Ello no obsta a que en el pleno del 11 y 13 de junio en el que se produce el consenso sobre las partes a presentar en Salónica, el Presidente confirme que pedirá al Consejo que prorrogue el mandato de la Convención para concluir las Partes III y IV. 
Tratados comunitarios. Al final, se opta por limitar su alcance a la revisión de un número limitado de disposiciones: aquéllas relativas a las políticas internas de la Unión contenidas en el Título III de la Parte III.

Respecto al procedimiento para llevar a cabo tal modificación se atribuye su iniciativa al Gobierno de cualquier Estado, al Parlamento Europeo o a la Comisión, proyecto que habrá de remitirse al Consejo Europeo. Tras consultar al Parlamento Europeo y a la Comisión, y, en su caso, al BCE corresponde decidir al Consejo Europeo por unanimidad.

39 En particular, en las sesiones plenarias de 24 y 25 de abril de 2003 ya señaladas, así como en las de 5 y 6 de junio, 11 y 13 de junio, 4 de julio, y 9 y 10 de julio de 2003.

40 Especialmente, vid. el documento de la Secretaría a la Convención (CONV 821/03), de 27 de junio de 2003, que contiene, con comentarios, el grueso de las diversas propuestas de enmienda recibidas en relación con el procedimiento de revisión del PTICE.

41 Las enmiendas que se incorporan a los sucesivos textos son las que se señalarán en el cuerpo del trabajo seguidamente, observándose que muy pocas pasaron la criba del Praesidium, cuyo Presidente señala desde muy pronto el carácter políticamente sensible de esta materia. Vid. el documento del Praesidium a la Convención de 26 de mayo de 2003 (CONV 728/03) en donde además de explicar las modificaciones que se aceptan e incluyen- iniciativa del PE así como la fase convencional y supresión de la facultad del Consejo de decidir si abre o no la GIG subsiguiente-, el Praesidium indica que descarta distinguir dos métodos distintos de reforma según afecten a las Partes I, II y IV o a la Parte III, por considerar que gran número de las disposiciones de la Parte III están estrechamente relacionadas con las restantes por lo que se les debe aplicar el mismo procedimiento de revisión. Al mismo tiempo, el Presidium propone que las futuras modificaciones entren en vigor con la ratificación de todos los Estados, ya que estima que lo contrario sería políticamente inaceptable, si bien indica que se podría establecer un procedimiento simplificado de revisión para algunas disposiciones políticamente menos sensibles. Esta postura la reitera en el Pleno de 11 y 13 de junio. Tanto es así, que en la sesión plenaria de 4 de julio de 2003, muchos miembros de la Convención hacen notar que la parte relativa a las disposiciones generales y finales no había sido aún objeto de un debate profundo ni de un consenso pleno, llegando Mme. Pervenche Beres a hablar de «hold-up sur la Partie IV» que demuestra la «lâcheté des gouvernements pour ne plus y toucher». Con posterioridad apenas se modificará el artículo, salvo la inclusión muy al final de su apartado 4.

42 Los convencionales ya desde la primera presentación del texto del artículo aprovechan la oportunidad para formular diversas propuestas dirigidas a pedir que se incluya en la iniciativa de la revisión al Parlamento Europeo e incluso a los Parlamentos Nacionales; a que se incorpore el método de la Convención como fase preparatoria de la CIG en la revisión; a reclamar métodos de revisión diferentes según se trate de modificar los elementos constitucionales y la CDF — método más exigente-, o se pretenda revisar las políticas y acciones de la Unión - proponiendo, en este caso, algunos convencionales que se abandone la unanimidad por una regla menos exigente como la ratificación por un umbral de 4/5 de los Estados-; e incluso otros miembros abogan porque la entrada en vigor de cualquier modificación futura sea posible con un umbral determinado de ratificaciones estatales, como 4/5, para evitar que en una Unión de 25 Estados un único Estado pueda impedir las revisiones. Sobre este último aspecto, abandono de la unanimidad, será muy vivo el debate en el pleno del 6 de junio de 2003, alegándose por algunos convencionales, entre otros extremos, que el hecho de introducir un procedimiento de retirada de la Unión autoriza a abandonar la unanimidad pues si no se produciría una unanimidad reforzada, o señalando, como hace Mme. Elena Paciotti, que si se quiere una Constitución digna de tal nombre hace falta organizar su ratificación por un procedimiento distinto puesto que constituye el rasgo fundamental para distinguir una Constitución de un Tratado Internacional clásico.

43 Derecho de iniciativa que no se le reconocía con anterioridad, lo cual era justamente criticado. Nótese, al respecto, que el modelo que se ha impuesto en la Teoría constitucional en relación tanto a la iniciativa como a las sucesivas fases de actuación del poder reformador, siempre se le reserva al Parlamento, como órgano fundamental del Estado por su conexión con el principio democrático, cumplir un papel decisivo. Cfr., por todos, DE VEGA, P., La reforma constitucional y..., op. cit., pp. 87-94, pp. 128-131. 
participación que se establecía para éste era en el caso de cambio del procedimiento especial al legislativo ordinario en donde el Consejo Europeo debía consultarle previamente. Ahora se necesita su aprobación en todos los supuestos contemplados especificándose la mayoría necesaria para aprobarlo. Por último, no se puede dejar de hacer notar que permanece inalterado que la decisión final otorgando la autorización pertinente corresponde al Consejo Europeo que ha de decidir por unanimidad.

Posibilidad de boqueo por cualquier Parlamento nacional, posibilidad de rechazo por el Parlamento Europeo, posibilidad de veto por un Estado en el Consejo Europeo, limitación de su aplicación a un ámbito o caso determinado previamente en la Parte III,... En fin, todo ello puede originar una pérdida de la eficacia de estos procedimientos previstos encaminados a permitir un grado mínimo de flexibilidad con la consecuencia de un aumento de las cooperaciones reforzadas.

De mayor importancia se presenta la adición de un nuevo artículo, el artículo IV-445 ter, relativo al «Procedimiento de revisión simplificado relativo a las políticas y acciones internas de la Unión» estipulando:

«1. El Gobierno de cualquier Estado miembro, el Parlamento Europeo o la Comisión podrán presentar al Consejo Europeo proyectos de revisión de la totalidad o parte de las disposiciones del Título III de la Parte III relativa a las políticas y acciones internas de la Unión./ 2. El Consejo Europeo podrá adoptar una decisión Europea que modifique la totalidad o parte de las disposiciones del Título III de la Parte III. El Consejo Europeo se pronunciará por unanimidad previa consulta al Parlamento Europeo y a la Comisión, así como al Banco Central Europeo en el caso de modificaciones en el ámbito monetario. Dicha decisión europea sólo entrará en vigor después de haber sido aprobada por los Estados miembros, de conformidad con sus respectivas normas constitucionales./ 3. La decisión europea contemplada en el apartado 2 no podrá aumentar las competencias atribuidas a la Unión por el presente Tratado»

Se observa como con tal prescripción se acogen en parte las tesis que se habían suscitado con anterioridad y a las que ya nos hemos referido en relación a establecer un procedimiento de revisión más flexible para parte de las disposiciones contenidas en los

44 Previsión que se reproduce literalmente en la Declaración al acta final de firma del TICE para la entrada en vigor del mismo. Entrada en vigor que se regula en el art. IV-8 sin cambios respecto el procedimiento seguido hasta el momento, esto es, ratificación por cada uno de los Estados conforme sus normas constitucionales, depósito de todos los instrumentos de ratificación, y entrada en vigor cuando esos requisitos se hayan cumplido.

45 De especial interés resulta el documento CIG 46/03 de 11 de noviembre de 2003, remitido por la Presidencia italiana a las Delegaciones nacionales, en el cual se proporcionan los antecedentes y cuestiones que han de abordarse respecto a la revisión del Tratado habida cuenta de las distintas posturas que existen de las Delegaciones nacionales sobre esta materia de las cuales da sucinta cuenta. Ante esas divergencias, la Presidencia propone posibles criterios de trabajo para llegar a un acuerdo que constituyen, en cuanto a su enfoque, el precedente de su redacción final.

46 En el apartado primero se añade que el Consejo ha de remitir dichos proyectos al Consejo Europeo y se clarifica que corresponde también al Consejo llevar a cabo la notificación a los Parlamentos nacionales. En el apartado cuarto, en vez de aludirse a que «el Consejo Europeo examinará la cuestión» se cambia por «el asunto se remitirá al Consejo Europeo», expresión que nos parece mucho más correcta aunque sigue sin despejar los interrogantes sobre las consecuencias jurídicas, si es que puede haberlas, de tal reenvío. 
podemos ir tan lejos. La praxis y la doctrina señalan que existen una serie de rasgos que permiten calificar a un proceso constituyente como verdaderamente democrático. Aunque tales rasgos no se verifican en todos los casos, cierto es que cuanto más se acerquen al modelo más certeza existe de que el resultado se corresponde con el concepto técnico de Constitución en su sentido moderno. El primero de los rasgos que se suele apuntar se refiere a la conciencia clara de la existencia de un proceso constituyente que busca elaborar y aprobar una auténtica Constitución. ¿Se ha producido este fenómeno?

Nos tememos que no pese al intento incuestionable por parte de las Instituciones europeas de resaltar este aspecto, pues esta intención no se manifestó abiertamente en las diversas instituciones estatales ni en los medios de comunicación ni en partidos políticos europeos como canalizadores de la participación ni en la sociedad civil. También se precisa que la elaboración de tal Norma Suprema sea llevada a cabo por representantes expresamente elegidos por los ciudadanos para este propósito. La composición y método de trabajo — consenso- de la Convención y la posterior CIG están bien alejados de ello. Quizás se pueda pensar que este proceso pueda culminarse con la posterior ratificación en cada uno de los Estados miembros. Quizás. Pero las circunstancias de las trece colonias en los Estados Unidos en el siglo XVIII no son ni remotamente parecidas a la existencia de Estados Constitucionales consolidados en el umbral del siglo XXI y al sentido que demanda la democracia actualmente.

Por todo ello, siempre vuelve a aparecer la misma pregunta ¿existe un titular del poder constituyente único capacitado para aprobar tal Constitución? ¿Se está dando hoy el pacto social y el acto constituyente por los cuales los pueblos de los Estados miembros deciden formar una unidad que como tal decide soberanamente sus valores básicos y estructura y limita el ejercicio de los poderes públicos?

En definitiva, siempre se vuelve al problema de la existencia o no de un pueblo europeo, a discutirse cuál es el concepto básico de la definición de ese pueblo europeo — ¿sociológico, cultural-histórico, jurídico? Sea de ello lo que sea, entendemos que lo determinante es que exista la voluntad consciente y libre de querer construir unitariamente una organización política. Que las razones sean unas u otras no nos parece lo relevante. Y entendemos que la única forma posible de saberlo es analizando el contenido, ratificación y procedimiento de reforma de esta hipotética Constitución Europea.

Realmente, creemos que el Tratado Constitucional es un paso más dentro del llamado proceso de constitucionalización de la Unión Europea. Proceso que, en el fondo, más parece una crisis constitucional existencial que se arrastra en el tiempo. En este sentido, entendemos que ha de considerarse otro Tratado comunitario con el mismo valor que los precedentes. Cierto es que mejora y sustituye a éstos, y que contiene modificaciones de relieve encaminadas hacia una mayor comprensión y estabilización del sistema. En este sentido, hay que destacar que supone un loable intento de acabar con la vertiginosa cadena de reformas en intervalos temporales cada vez más breves que sacude a la Unión Europea, estableciendo sus valores y principios claramente, proporcionando unas bases para su funcionamiento estable para los próximos 20 o 30 años. Pero no deja de ser deudor de los

47 Acogiendo así lo ya manifestado por algunos convencionales en la fase de la Convención sobre su más adecuada ubicación dentro de las Disposiciones finales al tratarse la revisión del Tratado. 
No habrá Convención ni CIG, pero se necesita la aprobación por todos los Estados conforme sus normas constitucionales. Y se añade, como cautela, que no se puede mediante esta decisión incrementar las competencias atribuidas a la Unión por el Tratado.

En realidad, se observa que con esta inclusión se acoge la tesis, ya planteada desde hace algún tiempo que después recogen algunos convencionales y que nuevamente será objeto de debate en la GIG entre las distintas Delegaciones nacionales, de permitir la revisión de las políticas comunitarias por un procedimiento simplificado de revisión. Y, en efecto, entraña una simplificación por cuanto no existe obligación de convocar una Convención ni una CIG. No obstante, hace falta unanimidad en el Consejo Europeo seguido de ratificación nacional en todos y cada uno de los Estados miembros al tiempo que se especifica expresamente que en ningún modo el uso de tal procedimiento en tales materias podrá conllevar un aumento de las competencias de la Unión. De este modo, con esta previsión se da un pequeño paso para asegurar alguna flexibilidad en las políticas comunitarias sin que de todos modos se vaya demasiado lejos.

En suma, bastantes novedades pero no sustanciales. La férrea regla de la unanimidad estatal, el predominio intergubernamental y, por lo general, la remisión a la ratificación nacional en todos y cada uno de los Estados se mantienen. Mecanismos que persiguen la defensa de la soberanía de cada uno de los pueblos de los Estados miembros. Por ello, el resultado será, en todo caso, una regla convencional y no una Constitución.

\section{V. ¿CONSTITUCION O TRATADO?}

Los problemas básicos en la UE siguen siendo los mismos que se arrastran en el diseño integrador desde su origen. Lo novedoso es la toma de conciencia pública de éstos y el diseño de un procedimiento amplio y abierto para buscar soluciones donde emerge, desde el propio Consejo Europeo, el debate sobre la necesidad de dotar a la UE de una Constitución, lo cual significa el reconocimiento que pese al llamado proceso de constitucionalización de la UE, actualmente no la tiene. Pero poco más allá de esto, pues otra vez nos encontramos que ha de ser una CIG la que de acuerdo con el procedimiento establecido desde el principio ha de acordar las reformas por unanimidad seguida de la ratificación acorde con sus normas constitucionales de los Estados miembros. Procedimiento que, además, se mantiene para el futuro. A esto hay que añadir que también se mantiene el régimen vigente para la propia entrada en vigor del Tratado Constitucional que aparece formalmente como una revisión de los anteriores Tratados, así como en el procedimiento de admisión de nuevos Estados. Más aun, por primera vez se recoge expresamente en el artículo I-60, en la Parte I, la retirada voluntaria de la Unión.

La creación de la Convención se ha saludado por parte de algunos sectores como el nacimiento de la «Convención de Filadelfia comunitaria» en clara comparación al proceso de elaboración de la Constitución federal estadounidense. Si esto es así, hay que deducir que no se han de seguir necesariamente las previsiones expuestas sobre el procedimiento previsto por estar en presencia de un poder constituyente originario que no se basa en la legalidad precedente sino que busca constituir o fundar otra distinta sin estar sujeto a límites. Por lo tanto, la pregunta crucial es si estamos ante una etapa propiamente constituyente. Sólo el futuro lo puede decir, pero hay datos que parecen indicarnos que no 
fundamentos constitucionales que sustentan la integración ni pueden superar los límites que las actuales Constituciones imponen a la integración europea.

En todo caso, habrá que estar atento al proceso abierto para proceder a su ratificación en los actuales 25 Estados miembros. 
